\title{
Analysis of problem-based learning models by typology of knowledge Pollock and Cruz (1999)
}

\author{
Iim Imandala ${ }^{\mathrm{a}, 1, *}$, Rumi Li ${ }^{\mathrm{a}, 2,}$, Agus Supriyadi ${ }^{\mathrm{a}, 3^{*}}$ \\ ${ }^{a}$ Nanjing Normal University, China \\ ${ }^{\mathrm{b}}$ Nanjing Normal University, China \\ ${ }^{c}$ Nanjing Normal University, China \\ ${ }^{1}$ iim_imandala75@yahoo.co.id; ${ }^{2}$ lirumi1964@163.com ; ${ }^{3}$ agus_dea@yahoo.com
}

* corresponding author

ARTICLE INFO

Article history

Received 2019-04-21

Revised 2019-05-04

Accepted 2019-05-25

Keywords

Problem-based learning models

Typology of knowledge

Doxastic theory

Nondoxastic theory

Internalism theory

\section{ABSTRACT}

Problem-based learning (PBL) is learning where students build knowledge based on learning experiences to solve problems. This model generally is known by teachers around the world and successfully attracted many researchers. However, very limited study has been conducted to analyse this learning model using the typology of knowledge by Pollock and Cruz (1999). This paper analyzed the PBL model using Pollock and Cruz instrument. This study discovered that learning knowledge and facilities contributed to the success of the learning process. However, the internalism typology instrument recommends for the teacher to select and choose appropriate knowledge. Particularly in specific student experience and scaffolding in constructivism through identification and screening system. Another instrument is externalism typology, found that the absorbs of knowledge depends on the developmental age and group compositions, primarily, in first-third grade students. This instrument suggested that a teacher must be more active to be facilitator and mediator in the absorption of knowledge through the assimilation and accommodations mechanism.

\section{Introduction}

The education quality determined by many factors, including the curriculum, teachers, facilities and infrastructure, education budget, and other learning resources[1][2]. The teacher factors have a strategic role in improving education quality. Teacher role in the classroom not only to teach but also as a facilitator, mediator, and some time as a friend as well as a parent. The various roles of the teacher considered as the critical success to the learning process and enhance the education quality [2]. The important factors for teachers are competences improvement. The government programs, almost in every country, emphasize on improving teachers competencies [3]. The best teachers never stop studying to improve his abilities, by government structured as well as independently.

The government in all over the world has numerous teacher training programs, especially teaching method training. Facts, today curriculum, is a student-centered learning model, imply teacher must be mastering many teaching methods and models. The teachers who can master various models and teaching methods will produce good quality learning processes [4], [5]. Through multi-capability, the teacher can deal with various circumstances, student's abilities, and student achievement. Previous research revealed that competent teachers have a high correlation to students learning achievements [6]. 
Various teaching models and methods need to analysis to adapt to the situation and conditions of student abilities. Therefore, the objectives of the present analysis here are to support educators or teachers in determining learning models that are appropriate to the students learning needs and situation.

The multifarious learning models are appropriate for learning. But for the present situation, it is not only needed a good learning model, but the most important is an innovative and contextual learning model [7]. One of the creative learning models that exist is Problem- Based Learning (PBL) a learning model based on the constructivist understanding and involves cognitive development that accommodates student participation in education and solving authentic problems [8] [9]. In prior research explained problem-based learning as a suitable method for constructivist approaches because it allows students to associate their previous knowledge with newly acquired knowledge while working in groups [10]. However, this paper was developed to answer as follow: is this Problem Based Learning model good in nature? Moreover, is the conceptual, planning, and applying of the ProblemBased Learning (PBL) model able to support the students to achieve knowledge? To answer these questions, this paper use, critical literature review analyses through a typology of knowledge propose by Polloc and Cruz [11]. The result of the review had discovered several areas need to be prepared when PBL used as a method of teaching.

\section{Content of Problem Based Learning (PBL)}

\subsection{Study of the nature of Problem Based Learning (PBL)}

The PBL model begins with the fact that many students who graduated are less able to applying the knowledge to solve problems in daily life [12], [13]. Hence, PBL focuses on the learning process and problem-solving. Also, achieve the learning objectives and learning activities centered on real student life [14].

The PBL developed on the belief that schools must become a laboratory to solve real-life problems [15]. Problem-solving related to the environment and daily life, particularly in the school such as classroom management, presenting the atmosphere of learning, as well as parent and school relationship. In the model of the development of problem-based learning, the problem and how to think as the center of learning can fulfil the student's desire to explore their meaningful situations about the real case [16]. Thus, the active involvement of students in the PBL remains the primary method. There is no learning when teacher more dominant teaching and students low embroiled in learning [17]. The PBL models accommodate student involvement in authentic learning and problemsolving. Therefore, PBL can be stated as a practical appearance in constructivist perspective. Learning is a capital to construct knowledge inside a learner undergo scaffolding to achieve a zone of proximal development [18][19]. The PBL contain dominant constructivist notions [20] because in obtaining information and conceive of learning topics, students learn how to construct a problem framework.

Children in any cognitive development stage are necessary to actively involved in learning to accommodate their fundamental knowledge (scheme), nevertheless with the new knowledge they get through their learning experiences [19]. Even more thus in school-age children, they will increasingly be able to construct their experiences and knowledge because of the learning process variables impact. Furthermore, pupils work in a small group, then organize and investigate problems, collect and analyze data, compile facts and build arguments regarding problem-solving, as well as work individually or collaborate on problem-solving [21]-[23]. For instance, during the process, there are interaction and communication within it. The student interaction and communication will be arising ideas exchange, the task distribution, or classically solving problems. While the interaction with the teacher occurs, the teacher experiences closeness with students in the teacher-assisted instruction process [24].

In The PBL model, the teacher role is not dominant to teach but facilitate a learning process. The teachers in, as facilitator and negotiators, still need to conduct effective social interaction with students display in defining and clarifying problems [25]. Social interaction in the learning context, accompany teachers and students to the characteristic circumstance. The character interaction in the PBL is involved in sociocultural constructivist ideology [26]. The inlet of the PBL process to the constructivist comprehension is not limited to how students solve problems, but also how to use that knowledge to resolve more complex issues in their lives. Various way solving a problem will provide 
appropriate provision for students in addressing the real problems that exist in everyday life [27]. In another word, the subject matter becomes the topic of learning needs transformed into a more contextual form.

The PBL was related to contextual learning in elementary school. In this situation, the culture encourages students to link knowledge and experience in school with their life [28]. No exaggeration to note, PBL and contextual learning model is very suitable to be applied to elementary school-age children. These learning models precisely to the concrete operational stage in cognitive development [29]. Cognitive and constructive processes become intermingled in PBL, thus supporting student learning the progress.

Based on the kinds of literature above, the fundamental of PBL is intended to assist students in acquiring knowledge and using that knowledge in solving problems in daily life. The base of this learning model is well developed and applied, because of this model based on several learning theories, constructivist understandings, and contextual approaches. The PBL model has positive impacts on students as expected by this learning model itself.

\subsection{Conceptual Definition}

According to Paul Eggen and Don Kauchak [30], PBL is a model of teaching, that uses problems as a focus for developing problem-solving skills, teaching material (content), and student self-control. In this learning model, a student identifies which problem meaningful in their study. The results of previous studies stated that PBL is motivating, challenging, and fun learning approach that results from the process of working towards understanding or solving problems [31], [32]. Another definition by Gewurtz et al. [33] stated, that PBL is a learning model based on the constructivist understanding, so that accommodates student's involvement in authentic learning and problem-solving. From some of these definitions, it can be concluded that PBL is a learning model that focuses on solving problems in obtaining an understanding. The main ideas of PBL are problem-solving, constructivism, students centered, related to original life, and work in a small group.

The PBL characteristics according to Graff and Kolmos [34] divided into three parts; PBL as theory, model, and practice. PBL as theory is built on three knowledge frameworks and truth justification, as stated by several studies, that PBL is built on beliefs in the learning experience, reflective constructivism, and social learning [35]-[37]. The knowledge framework in the learning experience is formed through the existence of fact modalities in learner itself. Internal modalities analyzing external facts as a comparison and experience, so PBL has a character of the learning experience. The characteristics of constructivism lead to the realization of knowledge caused by the process of identification, screening, accommodation, and assimilation of facts. In the context of social learning, it has the characteristic of learning to believe the truth based on something tangible from the learning environment.

The PBL has characteristics as a teaching and learning model which is coverage learning approach, methods, strategies, and evaluation. Refers to Affandi et al. [38] stated, the learning model is a systematical procedure to earn teaching and learning goals, furthermore learning model contain learning approach, method, strategy, teaching technic, learning media, and evaluation. Consequently, PBL is in accordance with the learning and teaching model, with reasons consistent with the definition of the learning model by Tayeb [39].

The PBL has attribute as practice, that attribute is identified and assessing the learner, decide teaching and learning goals, lesson plan, methods, determine the problem, students centered and work in a small group, learner finds knowledge to solve a problem, and measurable [40]. Sockalingam and Schmidt [41] more completely argue, this learning model has eleven feature; lead to learning issues, trigger interest, be of suitable format, stimulate critical reasoning, promote self-directed learning, be of suitable clarity, be of appropriate difficulty, enable application or use, relate to prior knowledge, stimulate elaboration, promote teamwork. The essence of problem-based learning is giving students real and meaningful issues that can use as stepping stones for the investigation and discovery process. Therefore, the learning conditions that occur are characterized by an openness situation, student's active involvement, and freedom atmosphere of thought. 


\subsection{Planning of Problem Based Learning}

In implementing the learning model, it has become a standard rule that there must be planning before it is implemented in the learning and teaching process. Many previous studies have shown the standard rules of PBL models, that PBL requires proper planning so that students and teachers succeed in achieving the expected learning goals [42]-[44]. Learning planning helps teachers or educators so that learning goes as expected. This planning process needs to be done so that the PBL implementation model is effective and efficient.

1. Several researchers have compiled and implemented PBL planning steps [45]-[47]. Leastwise three steps to prepare the problem-based learning model to consider as follows;

2. Determine goals and objectives. It stages very important to determine goals and objectives clearly so that they can be communicated well and clearly to students. Teaching and learning aims must consider the assessment of student abilities and learning needs.

3. The teacher is designing the right problem situation. Good problems must be authentic, confusing, provide space for collaboration, and be meaningful to students.

4. Organizing logistics resources and planning. This organizing relates to the learning resources, tools, and facilities that students use in solving problems, also followed by the teacher designs groupings of students to work in small groups.

\subsection{Applying of Problem Based Learning}

It is the nature of PBL that PBL is a learning model that has systematic stages PBL model systematically encourages and directs students to learn independently [48]. The teacher and student are actuating this learning model under predetermined planning. The systematics of the implementation of PBL is a careful way so that students can find a variety of knowledge to solve problems presented by the teacher. The phase of the PBL implementation has been summarized from Hemker and Prescher [49], Al-Naghar and Boryshev [50] as follow:

Phase 1: Direct students to problems. The teacher determines the learning objectives, explains the central equipment, directs and motivates students to engage in problem-solving activities.

Phase 2: Organizing students to learn. The teacher helps students determine and organize learning tasks related to the problem.

Phase 3: Independent and group investigations. The teacher encourages students to collect data, carry out experiments, and seek explanations and solutions independently and in groups.

Phase 4: Develop and present work. The teacher assists students in planning and preparing work results such as reports, videos, and examples, and helps them share work with others.

Phase 5: Analysis and evaluation of the problem-solving process. The teacher helps students to reflect on the results of their investigations and the methods they use. The final phase of problembased learning has activities that aim to help students analyze and evaluate their thought processes such as the investigations and intellectual abilities they use.

\section{Problem Based Learning Model Analysis based on John Pollock and Joseph Cruz (Typology of Knowledge, 1999)}

\subsection{Typology of Knowledge Theories}

Pollock and Cruz are epistemologists who wrote a book titled the Contemporary Theories of Knowledge in 1986, then in 1999 published the second edition in the same title. The book discusses the epistemology of knowledge and truth. In the epistemology discussion, there is a description of the typology of knowledge. Using typology, it used as a medium to analyze various learning models and methods. It is generally recognized that learning is one channel for gaining knowledge. Therefore, PBL as a learning model to obtain knowledge, it can be analyzed through the typology of knowledge. Know how to obtain knowledge by way of philosophy review helps educators in implementing a learning model.

In the philosophy of science states that the model of learning and teaching must provide essential knowledge for students' life. Knowledge gained by students can be useful when they are learning and 
useful for their lives outside the classroom and in life in the future. Therefore, based on Pollock and Cruz's thought, valuable knowledge in learning and teaching has several typologies of knowledge theory, namely:

\subsection{Doxastic Theories}

Knowledge naturally exists in the individual in the form of physical and psychological modalities. For the time being, modalities formed into potential knowledge, then life experiences forge into knowledge. Belief is born as knowledge originating from an individual and not affected by external variables (nondoxastic variable).

The external knowledge as a result of different individuals and places is comparative knowledge. The external knowledge variable is not a foundation and trust, but as an addition to strengthening existing internal knowledge. Finally, the process will occur whether the knowledge is rejected or collaborate with existing beliefs.

\subsection{Nondoxastic Theories}

The nondoxastic theories are in contrast to the doxastic assumption. This theory believes truth is not only coming from oneself but also influences from external variables. External factors influence existing knowledge and become an acceptable source of truth. Nondoxastic theories stated, trust from outside the dominant individual to form knowledge and accepted the truth. So knowledge is not only obtained from oneself but also facile from external variables. The truth of knowledge needs to be approved by knowledge and credence from outside.

\subsection{Internalism Theories}

The theory of Internalism is almost the same as the Nondoxastic theory. This theory accepts knowledge obtained from one's own beliefs but still receives knowledge from external variables. External knowledge cannot change internal beliefs so that internal knowledge remains strong. So the external knowledge variable is only strengthened. The rejected of external variables cannot accept, must be ignored.

The information scattered outside need to be identified and screening according to internal knowledge needs. Identification instruments are a result of deep cognitive internalization. Identification aims to find information that matches internal trust and variables. The process of Internalism theories does not reject knowledge or beliefs from the external but needs to be filtered first. Although there is information subjectivity caused the perception factor, internal knowledge has a screening mechanism to minimize subjectivity.

The information received through perception is a natural process in strengthening internal knowledge. The belief in internal knowledge is increasingly crystallized by the acquisition of already selective information. This information not only becomes an extension but also becomes new truth knowledge from the internal. Even from this internal knowledge will bring new knowledge elements to external knowledge variables. Thus actual knowledge and beliefs, as well as external truths, are the result of internal knowledge.

\subsection{Externalism Theories}

The external theories believe that knowledge and truth, as well as individual beliefs. External variables are a very dominant influence so that it can form cognitive knowledge schema internally. This theory does not deny the existence of internal knowledge potential brought by each. External theories state that individual internal knowledge cannot actually without a strong influence from the external variables. The knowledge potential will not change if there is no significant influence of external knowledge.

Refers to this theory, Internal knowledge does not have internal screening and identification boundaries. Information from outside enters and affect the knowledge scheme's potential. Internal knowledge modalities only have accommodation and assimilation mechanism that continue working due to stimulation of the external knowledge variable. The potential is there to be actual because resurrected by accommodation and assimilation. External information variables login to the perception stage then processed through assimilation. The results of the assimilation process stored in particular locus and accommodating as knowledge, also shaping believe in the truth. 


\section{Results and Discussion}

Based on the previous literature review, there have been many analysis and criticisms of the PBL model. In this section, the results and analysis of the dimensions of nature, conceptual content, planning, and applying of PBL will be presented. The analysis instrument used is The Typology of Knowledge Pollock and Cruz (1999).

\subsection{Doxastic Theories}

The nature of PBL is finding and determining knowledge to solve problems through modalities in students. A problem that must find the solution is a real-life problem, especially in accordance with the student development stages. Even though students work in groups, they still used their internal knowledge to answer the problem. When working in groups, other group member knowledge is only taken into consideration. This perspective analyzed using doxastic theories, PBL has a nature that is accommodating to doxastic theories. The accommodative evidence is on the student independence determining knowledge to problems solving.

The PBL model encourages students to prove the truth or belief in certain learning form and situation, thus approaching to real life. Through problems to approach real-life encourage students to obtain their knowledge and trust in their solutions independently. PBL entirely directs students to become independent in conducting inquiry based on their knowledge capital.

The doxastic theories point of view to the conceptual content of PBL is learning model has internal characteristics modalities that influence external variables. So knowledge in students is more dominant affecting the external environment. Build upon doxastic, in the learning life; students get outside consideration of themselves to gain knowledge. Therefore teachers and students must selective in choosing the appropriate knowledge to be used as problem-solving.

The PBL model helps students in planning and preparing the presentation of solutions to problems, and helps them to share assignments with their friends. Students study the problem also design an action plan to work on the issue. The teacher only facilitates the activity, so that runs smoothly. The situation is consistent with the doxastic theory typology that the decision to take specific knowledge depends on the trust. Proof in the realm of this theory requires proof and verification by within they self.

In the learning process, students behave independently in their learning and discovering the solution, so react proves the PBL models have the doxastic theories typology. In line with this theory, internal knowledge modalities have strongly affected the external variables. The teachers present acted as facilitators and mediators, so that prevent collisions between belief and knowledge of students.

\subsection{Nondoxastic Theories}

The nondoxastic theories have an argument that the influence of external variables is powerful to form knowledge in students. External influences trigger potential knowledge modalities in students until the facts and truths of knowledge arise in students. It is the nature of the PBL model to provides opportunities for external influences such as environmental variables that encourage students to solve problems. By the collaboration appearances in groups are parts of empowering environment to find knowledge.

Nondoxastic viewpoint direct educators, when planning PBL, it is necessary to consider the learning environment variables. The knowledge facts need preparing conveniently with prior learning experiences. Also, it is also necessary to analyze the learning achievements and assessment proceeds of developmental stages. Designing a lesson plan does not only focus on material or knowledge but also needs to be prepared for structuring learning facilities.

The nondoxastic believes that environmental influences are powerful, for example, the teacher influence. But in the PBL model, the teacher influence is placed as a mediator and facilitator, and not the only knowledge resources. The teacher facilitates students to find knowledge which exists in their environment. The teacher also mediated when there were conflicting opinions in group work.

In the way of establishing a group, the group member composition must create conducive learning situation. The composition of groups is not homogeneous, so group members consist of various learning abilities and student characters. Variations in a group member will provide a variety of scaffolding, so students learn to choose beneficial influences. Also, students will earn benefit from a 
variety of interactions and communication. Students discuss problems in a small group and comparing ideas to each other. Students also clarify the case facts and then define a problem. They not only work individually but also work in groups to support each other in solving problems. Brainstorming his ideas in the discussion is very good by relying on prior knowledge. Also, they identify what they need to resolve the issues and what they do not know.

Nondoxastic theories view the importance of something other than trust as a function of previous beliefs, also consider other important things beyond belief itself. Thus, a conclusion is considered accurate not only based on self-knowledge, moreover by considering other thoughts. With the principle of defeasible, correct knowledge in a particular environment may be wrong in different environments. This process occurs in the problem-based learning model. Students exchange ideas to solve problems and look for other sources of knowledge. The source can be obtained from the teacher, the surrounding environment or other media. External source affecting internal knowledge variable and belief, initially dominant clout by learning environment. In this condition, it can be concluded PBL has nondoxastic typology.

\subsection{Internalism Theories}

According to internalism theories, internal knowledge forming through a gradual and measurable process. Such a process will shape rational decisions and give internal access to each other's different experience. The basic principle of PBL models has a progressive and quantifiable process as expected by internalism theories. Internal knowledge is very strong, yet PBL still gives values to environmental influences.

Internalism theories inspire PBL to developmental assessment and academic dimension. The teacher, when a design lesson plan is according to the results of the assessment or it can be assumed that learning is student-centered. Even though learning builds upon student-centered, learning experience factor still becomes the basis for planning teaching and learning. However, teachers as facilitators and mediators need to contrive the process of identifying and screening knowledge from externally.

Every stage of PBL discovered internal access to absorbs knowledge possessed by students. It proceeds new information that is perceived selectively and arranged according to rational explanation. Moreover, student based on their ability should be able to capture meaningful learning for their life in every stage.

Learning stages in this learning model show the identification and knowledge screening to the external variable which intervenes to internal believe and truth. Through typology internalize then PBL model requires strengthening teacher role in the learning process. The teacher role as mediator and facilitator drive identification and screening knowledge from the learning environment. Of course, a student will grasp how to defend internal modalities.

The internalize typology criticism of PBL is that students at grade or certain age cannot reveal what is most important to learn, especially in areas where a student who does not have experience. A Teacher must selective to choose any knowledge.

\subsection{Externalism Theories}

The knowledge learned by students is a part of the learning environment. This circumstance of knowledge obtained through the problems of life that brought into the learning process. The purpose of life from the external classroom and the student's self is an essential problem in externalism theories.

Pollock and Cruz did not reject the existence of external influences to shape knowledge. The power resources in this learning model are problems of everyday life. This problem is a remarkable phenomenon to encourage learning. PBL models following the views of externalism theories which consider that real problems in life exist in the process of learning and teaching. In the end, it will form knowledge for students as provisions for their current and future lives.

On the preparatory dimension, the external theory requires preparation in the maturity of internal knowledge modalities. Maturity what it meant is readiness for assimilation and accommodation of knowledge. Thus, PBL planning prepares scaffolding and social development to enter the assimilation 
and accommodation process. Based on externalism theories, PBL prepares a learning environment without ignoring internal knowledge.

The externalism typology in the criticism dimension to PBL is that assimilation and accommodations mechanism in externalism typology depends on the developmental age and group compositions. The knowledge mechanism earns effectively when learning environment proper to the internal variable. Implementation of this learning model in first- third grade, pupils needs to carefully assess and account mental and social development. They are still dominant in ego centrist period. Hence, the teacher must be more active to be facilitator and mediator.

\section{Conclusion}

The nature of PBL is a learning model that presents contextual problems to stimulate students to learn. Through this learning process will be shaping knowledge in students. Learning that uses realworld problems as a context for students to learn about critical thinking and problem-solving skills, and to acquire essential knowledge and concepts from the subject matter.

Based on the typology of doxastic analysis according to Pollock and Cruz, PBL models are accommodative to internal knowledge modalities. Students independently use their internal knowledge to solve problems. PBL also makes plans according to students' abilities and learning experience, similarly, when the learning process is child-centered. In generally, PBL established knowledge through various source channels. The learning model can also add trust and confidence to the truth of facts and phenomena. PBL models encourage students to be more active and creative in solving a problem given by the teacher.

The nondoxastic typology analysis showed PBL placed the influence of knowledge from the environment as a mediator and facilitator. So, this learning model still recognizes the existence of the power of environmental influences daily life problems and become a source of reference. Moreover, in the learning process, it is interesting to note that learning knowledge and facilities are also contributed to the success of the learning process. However, internalism typology recommends for the teacher to select and choose appropriate knowledge in avoiding misunderstanding knowledge by a student. Particularly in specific student experience and scaffolding in constructivism through identification and screening system.

In externalism typology, the absorbs of knowledge depends on the developmental age and group compositions, primarily, in first-third grade students. During these periods the student highly dependent on learning environment especially the teacher. The externalism theories suggest a teacher must be more active to be facilitator and mediator in the absorption of knowledge through the assimilation and accommodations mechanism.

\section{References}

[1] S. H. Dunga, "An Analysis of the Determinants of Education Quality in Malawi: Pupil Reading Scores," Mediterr. J. Soc. Sci., vol. 4, no. March 2013, pp. 337-342, 2013.

[2] J. Muvawala, "Determinants of learning outcomes for primary education: A case of Uganda," $J$. Stat. Africain, vol. 15, pp. 42-54, 2012.

[3] OECD, ppt Building a High-Quality Teaching Profession - Cumbre Int 1. 2011.

[4] K. Trigwell, M. Prosser, and F. Waterhouse, "Relations between teachers' approaches to teaching and students' approaches to learning," High. Educ., vol. 37, no. 1, pp. 57-70, 1999.

[5]E. M. Ganyaupfu, "Teaching Methods and Students ' Academic Performance Teaching Methods and Students 'Academic Performance," vol. 2, no. September 2013, pp. 29-35, 2016.

[6] T. Kini and A. Podolsky, "Research Report: Does Teaching Experience Increase Teacher Effectiveness? A Review of the Research," 2016. 
[7]E. Suryawati and K. Osman, "Contextual learning: Innovative approach towards the development of students' scientific attitude and natural science performance," Eurasia J. Math. Sci. Technol. Educ., vol. 14, no. 1, pp. 61-76, 2018.

[8] C. E. Hmelo-Silver, "Problem-Based Learning: What and How Do Student Learn?," Educ. Psychol. Rev., vol. 16, no. September 2004, pp. 235-266, 2004.

[9] R. M. Marra, D. H. Jonassen, and B. Palmer, "Why Problem-Based Learning Works : Theoretical Foundations," J. Excell. Coll. Teach., vol. 25, pp. 221-238, 2014.

[10] D. Inel and A. G. Balim, "The effects of using problem-based learning in science and technology teaching upon students' academic achievement and levels of structuring concepts," Asia-Pacific Forum Sci. Learn. Teach., vol. 11, no. 2, pp. 1-23, 2010.

[11] J. L. Pollock and J. Cruz, Contemporary Theories of Knowledge, Second Edi. Maryland: Rowman \& Littlefield, 1999.

[12] D. Tillman, "Implications of Problem Based Learning ( PBL ) in Elementary Schools Upon the K-12 Engineering Education Pipeline," 120th ASEE Annu. Conf. Expo., 2013.

[13] M. Savin-Baden, “The Problem-Based Learning Landscape," Planet, vol. 4, no. 1, pp. 4-6, 2013.

[14] V. F. C. Servant-Miklos, "The Harvard Connection: How the Case Method Spawned ProblemBased Learning at McMaster University," Heal. Prof. Educ., 2018.

[15] R. I. Arends, Learning to Teach, 9th ed, Newyork: McGraw-Hill Companies, Inc., 2012.

[16] J. Dewey, "A restatement of the relation of reflective thinking to educative process," in How we think, Lexington, Massachusetts: D.C. Heath and Company, 1933, pp. 55-58.

[17] K. Yajma, Y. Hayakawa, Y. Kashiwaba, A. Takahshi, and S. Oiguchi, "Construction of Active Learning Environment by the Student Project," Procedia Comput. Sci., vol. 96, no. September, pp. 1489-1496, 2016.

[18] L. S. Vygotsky, Mind in Society, 2nd ed. Harvard University Press, 1979.

[19] J. W. Santrock, "Cognition and Language," in Child Development, Thirteenth., Newyork: Mc. Graww Hill, 2010, p. 168.

[20] E. H. J. Yew and K. Goh, "Problem-Based Learning: An Overview of its Process and Impact on Learning," Heal. Prof. Educ., vol. 2, no. 2, pp. 75-79, 2016.

[21] T. A. Nicholl and K. Lou, "A Model for Small-Group Problem-Based Learning in a Large Class Facilitated by One Instructor," Am. J. Pharm. Educ., vol. 6, 2012.

[22] J. Khumsikiew, S. Donsamak, and M. Saeteaw, "A Model of Small-Group Problem-Based Learning In Pharmacy Education: Teaching in the Clinical Environment," IAFOR J. Educ., vol. 3, no. 2, 2017.

[23] J. Merritt et al., "Problem-Based Learning in $\mathrm{K}-8$ Mathematics and Science Education: A Literature Review The Interdisciplinary Journal of Problem-based Learning Special Issue On Competency Orientation in Problem-BasED Learning Problem-Based Learning in $\mathrm{K}-8$ Mathematics a," vol. 11, no. 2, pp. 5-17, 2017.

[24] W.-Y. Lu and A. Jian, "Study on Teacher-Student Interaction in the Ideological and Political Theory Teaching Based on SPOC Model," in 2nd Annual International Conference on Social Science and Contemporary Humanity Development (SSCHD 2016), 2016, no. Sschd, pp. 365369.

[25] P. K. Sahu and B. Sa, "Tutor's Role in Problem-based learning: Minimum Interference with Maximum Responsibility,” J. Multidiscip. Contemp. Res., vol. 1, no. 2, pp. 1-9, 2015.

[26] Martin J. Packer and Jessie Goicoechea, "Sociocultural and Constructivist Theories of Learning: Ontology, Not Just Epistemology," Educational Psychologist, vol. 35, no. 4. pp. $227-$ $241,2000$. 
[27] A. S. K. Wong, C. W. P. Li-Tsang, and A. M. H. Siu, "Effect of a social emotional learning programme for primary school students," Hong Kong J. Occup. Ther., vol. 24, no. 2, pp. 5663, 2014.

[28] P. Hutchinson, "Children Designing \& Engineering: Contextual Learning Units in Primary Design and Technology," J. Ind. Teach. Educ., vol. 39, no. 3, pp. 122-145, 2002.

[29] D. Herawaty and W. Widada, "The Influence of Contextual Learning Models and the Cognitive Conflict to Understand Mathematical Concepts and Problems Solving Abilities," vol. 218, no. ICoMSE 2017, pp. 96-102, 2018.

[30] D. Kauchak and P. Eggen, Educational Psychology: Windows on Classrooms. 2016.

[31] A. Masek and S. Yamin, "The Effect of Problem Based Learning on Critical Thinking Ability: A Theoretical and Empirical Review," Int. Rev. Soc. Sci. Humanit., vol. 2, no. 1, pp. 215-221, 2011.

[32] H. S. Barrows, N. Tamblyn, and S. Jonas, Problem-Based Learning Preface. 1980.

[33] R. E. Gewurtz, L. Coman, S. Dhillon, B. Jung, and P. Solomon, "Problem-based Learning and Theories of Teaching and Learning in Health Professional Education," J. Perspect. Appl. Acad. Pract., vol. 4, no. 1, pp. 59-70, 2016.

[34] E. De Graaf and A. Kolmos, "Characteristics of problem-based learning," Int. J. Eng. Educ., vol. 5, pp. 657-662, 2003.

[35] N. F. Harun, K. M. Yusof, M. Z. Jamaludin, and S. A. H. S. Hassan, "Motivation in Problembased Learning Implementation," Procedia - Soc. Behav. Sci., vol. 56, no. Ictlhe, pp. 233-242, 2012.

[36] K. M. Yusof, S. A. H. S. Hassan, M. Z. Jamaludin, and N. F. Harun, "Cooperative Problembased Learning (CPBL): Framework for Integrating Cooperative Learning and Problem-based Learning," Procedia - Soc. Behav. Sci., vol. 56, no. Ictlhe, pp. 223-232, 2012.

[37] R. J. Savery, "Overview of problem-based learning: Definitions and distinctions," Essent. Readings Probl. Learn. Explor. Extending Leg. Howard S. Barrows, vol. 1, no. 1, pp. 9-20, 2014.

[38] M. Afandi, E. Chamalah, and O. P. Wardani, Method and learning model in the school, 1st Editio., vol. 392, no. 2. Semarang: UNISSULA PRESS, 2013.

[39] T. Tayeb, "Analysis and Benefits of Learning Models," J. Pendidik. Dasar Islam, vol. 4, no. 2, pp. 48-55, 2017.

[40] C. Eser and F. OzdamliI, "Features and characteristics of problem based learning," Cypriot J. Educ. Sci., vol. 11, no. 4, pp. 195-202, 2016.

[41] N. Sockalingam and H. G. Schmidt, "Characteristics of Problems for Problem-Based Learning: The Students' Perspective,” Interdiscip. J. Probl. Learn., vol. 5, no. 1, pp. 3-16, 2012.

[42] A. Mutallib, "The implementation of problem based learning to improve student achievement in Islam Religion Study," Pedagogia, vol. 3, no. 1, pp. 1-9, 1997.

[43] Redhana IW., "Problem based study model to improve critical and problem solve skill," $J$. Pendidik. dan pengajaran, vol. 46, no. 1, p. 11, 2013.

[44] S. A. Gallagher, B. T. Sher, W. J. Stepien, and D. Workman, "Implementing Problem-Based Learning in Science Classrooms," Sch. Sci. Math., vol. 95, no. 3, pp. 136-146, 2010.

[45] W. Hung, "Theory to reality: A few issues in implementing problem-based learning," Educ. Technol. Res. Dev., vol. 59, no. 4, pp. 529-552, 2011.

[46] A. Walker and H. Leary, "A Problem Based Learning Meta-Analysis: Differences Across Problem Types, Implementation Types, Disciplines, and Assessment Levels," Interdiscip. J. Probl. Learn., vol. 3, no. 1, pp. 6-28, 2012.

[47] A. Steinemann, "Implementing Sustainable Development through Problem-Based Learning: Pedagogy and Practice," J. Prof. Issues Eng. Educ. Pract., vol. 129, no. 4, pp. 216-224, 2003. 
[48] C. E. Hmelo-Silver, R. G. Duncan, and C. A. Chinn, "Scaffolding and achievement in problembased and inquiry learning: A response to Kirschner, Sweller, and Clark (2006)," Educ. Psychol., vol. 42, no. 2, pp. 99-107, 2007.

[49] L. Hemker, C. Prescher, and S. Narciss, "Design and Evaluation of a Problem Based Learning Environment for Teacher Training," Interdiscip. J. Probl. Learn., vol. 11, no. 2, pp. 5-17, 2017.

[50] R. A. Al-Naggar and Y. V Bobryshev, "Community Medicine \& Health Education Effect of SAFE Intervention on Pattern of Barriers to Trichiasis Surgery," J. Community Med. Health Educ., vol. 2, no. 7, pp. 2-5, 2012. 